\title{
GLYPHOSATE E NITROGÊNIO NO CONTROLE DE Brachiaria decumbens STAPF EM CAPINEIRAS ESTABELECIDAS ${ }^{1}$
}

\author{
Glyphosate and nitrogen in the control of Brachiaria decumbens \\ Stapf in established elephant grass stocking piles
}

\author{
Joadil Gonçalves de Abreu², Antônio Ricardo Evangelista ${ }^{3}$, Itamar Ferreira de Souza ${ }^{4}$, \\ Gudesteu Porto Rocha ${ }^{5}$, Lécio Queiroz Soares ${ }^{6}$, Leonardo de Castro Santarosa ${ }^{6}$
}

\begin{abstract}
RESUMO
O objetivo do experimento foi avaliar a eficiência de utilização do herbicida glyphosate associado com adubação nitrogenada no controle de Brachiaria decumbens Stapf em capineiras estabelecidas. O delineamento experimental foi em blocos casualizados, com dezessete tratamentos e três repetições. Os tratamentos foram arranjados em esquema fatorial $4 \times 4+1$, sendo quatro doses de glyphosate $(0,720,1440$ e $2160 \mathrm{~g} / \mathrm{ha} /$ aplicação), quatro doses de nitrogênio $(0,75,150$ e $225 \mathrm{~kg} / \mathrm{ha} / \mathrm{ano})$ e um tratamento adicional (testemunha com capina). As aplicações do nitrogênio e glyphosate, nas respectivas doses, foram realizadas imediatamente após o corte do capim-elefante. A associação entre o herbicida glyphosate $(2160 \mathrm{~g} / \mathrm{ha} / \mathrm{aplicação})$ e nitrogênio $(225 \mathrm{~kg} / \mathrm{ha} / \mathrm{ano})$ foi eficiente no controle de capim-braquiária em capineiras estabelecidas. A aplicação do herbicida glyphosate (2160 g/ha/aplicação) reduziu o tamanho do banco de sementes de capim-braquiária no solo em $64 \%$.
\end{abstract}

Termos para indexação: Capim-elefante, capim-braquiária, herbicida, adubação.

\begin{abstract}
The objective of this experiment was to evaluate the efficiency of the use of the herbicide glyphosate associated with nitrogen fertilization in the control of Brachiaria decumbens Stapf in elephant grass stocking piles. The experimental design used was a randomized blocks with 17 treatments and three replications. The treatments were arranged in $4 x 4+1$ factorial scheme, namely four doses of glyphosate $(0,720,1440$ e $2160 \mathrm{~g} / \mathrm{ha} /$ application), four doses of nitrogen $(0,75,150 \mathrm{e} 225 \mathrm{~kg} / \mathrm{ha} / \mathrm{ano})$ and one additional treatment (control with a hoeing). The application of the nitrogen and glyphosate, in the respective doses were performed immediately after the cutting of elephant grass. The association between glyphosate $(2160 \mathrm{~g} / \mathrm{ha} / \mathrm{application})$ and nitrogen $(225 \mathrm{~kg} / \mathrm{ha} / \mathrm{ano}) \mathrm{was}$ efficient in the control brachiaria grass in established elephant grass stocking piles. The application of the glyphosate ( $2160 \mathrm{~g} / \mathrm{ha} /$ application) reduced the size of the bank of brachiaria grass seeds in the soil in $64 \%$.
\end{abstract}

Index terms: Elephant grass, brachiaria grass, herbicide, fertilization.

(Recebido para publicação em 3 de março de 2005 e aprovado em 19 de outubro de 2005)

\section{INTRODUÇÃO}

O cultivo de áreas com forrageiras para corte constitui uma das alternativas propostas para aliviar o problema da falta de forragem na época mais crítica do ano (maio a setembro). Dentre as espécies mais usadas destaca-se o capim-elefante (Pennisetum purpureum Schum.), devido ao seu elevado potencial de produção de forragem e a sua boa palatabilidade.

As capineiras da Região Sul de Minas Gerais estão intensamente infestadas por Brachiaria spp., o que causa sérios prejuízos aos pecuaristas, pois essa infestação reduz a produtividade da capineira em razão da competição por água, luz e nutrientes.
A habilidade das espécies de Brachiaria em sobreviver a fatores adversos como o ataque de cigarrinhas-das-pastagens, seca prolongada, fogo e práticas culturais que visem a sua eliminação (aração, gradagem e aplicação de herbicidas) contribui sobremaneira para o reconhecimento geral de que as braquiárias são plantas de difícil erradicação (RODRIGUES \& REIS, 1994). A dificuldade de se eliminar as braquiárias tem sido atribuída principalmente às características morfológicas das plantas, à grande quantidade de sementes no solo, formando um banco de sementes e, eventualmente, a presença em algumas espécies de Brachiaria de compostos alelopáticos que inibem o crescimento de outras forrageiras (RODRIGUES \& REIS, 1994). O banco de sementes

\footnotetext{
Extraído da Tese de Doutorado, apresentada à Universidade Federal de Lavras/UFLA, pelo primeiro autor.

2 Engenheiro Agrônomo, M. Sc., Departamento de Zootecnia da Universidade Federal de Lavras/UFLA - Bolsista CAPES - Cx. P. 3037 - $37200-000$ Lavras, MG - joadil.goncalves@terra.com.br

${ }^{3}$ Engenheiro Agrônomo, D.Sc., Professor do Departamento de Zootecnia/UFLA - Cx. P. 3037 - 37200-000 - Lavras, MG - Bolsista CNPq.

${ }^{4}$ Engenheiro Agrônomo, D.Sc., Professor do Departamento de Agricultura/UFLA - Cx. P. 3037 - 37200-000 - Lavras, MG.

${ }^{5}$ Engenheiro Agrônomo, D.Sc., Professor do Departamento de Zootecnia/UFLA - Cx. P. 3037 - 37200-000 - Lavras, MG.

${ }^{6}$ Estudante de Graduação em Zootecnia, Departamento de Zootecnia/UFLA - Cx. P. 3037 - 37200-000 - Lavras, MG - Bolsista PIBIC-CNPq.
} 
apresenta dimensão espacial, considerando a distribuição horizontal e a vertical das sementes no solo, que refletem a dispersão inicial na superfície e a subseqüente movimentação no solo, e a dimensão temporal, mediante a dormência que distribui a germinação das sementes no decorrer do tempo (SIMPSON et al., 1989).

A B. decumbens apresenta propagação vegetativa por meio de rizomas e estolões, conferindo um grande poder de disseminação, uma vez que a planta-mãe é capaz de gerar dezenas de outras plantas. As sementes apresentam dureza tegumentar, podendo germinar no momento que caem no solo ou permanecerem dormentes por meses, sendo que essa dormência é característica fundamental na resistência à erradicação (RODRIGUES \& RODRIGUES, 1996).

Conforme Corsi (1994), estimulando o crescimento das espécies forrageiras tropicais com o do uso do nitrogênio, além da melhoria no valor nutritivo e do aumento na produção de matéria seca, reduz-se o número de limpezas da pastagem para combate às plantas daninhas.

Para capim-elefante, Cantarutti et al. (1999) recomendam seguir as orientações para sistemas intensivos de produção, com doses de $200 \mathrm{~kg} \mathrm{~N} / \mathrm{ha} / \mathrm{ano}$, fracionadas durante o período chuvoso (outubro-abril), após cada corte. Santos (1995) observou, para as condições de São Paulo, que o corte do capim-elefante deve ser efetuado ao nível do solo com freqüência de 60 dias no período das águas. O mesmo autor recomendou aplicação de 200 a $250 \mathrm{~kg} \mathrm{~N} / \mathrm{ha} / \mathrm{ano}$, de forma parcelada após cada corte no período chuvoso.

Experimentos com capim-elefante 'Napier' adubado com diferentes níveis de nitrogênio (50, 100 e $150 \mathrm{~kg} \mathrm{~N} / \mathrm{ha} /$ ano) na forma de sulfato de amônio ou consorciado com uma mistura de leguminosas forrageiras (centrosema, siratro e galáxia) foram realizados em Nova Odessa, São Paulo, durante vários anos por Lourenço et al. (1978). Nesse estudo, verificou-se que a maior expansão da invasora grama batatais (Paspalum notatum Flugge) ocorreu nos pastos adubados com $50 \mathrm{~kg} \mathrm{~N} / \mathrm{ha} / \mathrm{ano}$, enquanto a menor expansão se deu nos pastos recebendo $150 \mathrm{~kg} \mathrm{~N} / \mathrm{ha} / \mathrm{ano}$.

$\mathrm{O}$ incremento na produtividade do capim-elefante é decorrente, entre outras causas, do aumento da fertilidade do solo, sendo o nitrogênio o principal nutriente envolvido nas respostas à adubação, desde que outros nutrientes estejam presentes em quantidades adequadas e equilibradas. Desta forma, uma alternativa para reduzir a infestação de $B$. decumbens em áreas de capineiras pode ser a associação de métodos de controle, envolvendo o químico e o cultural. $\mathrm{O}$ controle químico, em pós-emergência tardia, atinge as plantas provenientes de propagação vegetativa e sexuada, além de poder ser feito dirigido e com mais economia em relação a outros métodos de controle. O controle cultural, por meio de adubações de manutenção, garante ao capim-elefante condição de elevada produtividade e competição com o capim-braquiária.

Objetivou-se com o presente estudo definir um nível mais eficiente do herbicida pós-emergente glyphosate associado à adubação nitrogenada no controle de $B$. decumbens em capineiras estabelecidas.

\section{MATERIAL E MÉTODOS}

O presente trabalho foi realizado em área do Departamento de Zootecnia da Universidade Federal de Lavras-MG. Lavras situa-se a $21^{\circ} 14^{\prime}$ de Latitude Sul e $45^{\circ} 00^{\prime}$ de Longitude Oeste de Greenwich, com altitude média de 910 m. O clima, segundo a classificação de Koppen, é do tipo Cwb (subtropical moderado úmido), tendo duas estações distintas: uma seca, de abril a setembro, e outra chuvosa, de outubro a março. A precipitação média anual é de $1493 \mathrm{~mm}$, com temperaturas médias de máxima e mínima de 26,0 e $14,6^{\circ} \mathrm{C}$, respectivamente (CASTRO NETO et al., 1980).

A capineira foi implantada em dezembro de 1999, com a espécie Pennisetum purpureum cv. Cameroon, em solo classificado como Latossolo Vermelho Escuro distrófico, textura argilosa. No primeiro (2002/2003) e segundo anos de avaliação (2003/2004) foram coletadas amostras de solo da área experimental para análise química (setembro/2002 e setembro/2003) (Tabela 1).

De acordo com os resultados da análise de solo foi realizada adubação de manutenção, que consistiu da aplicação anual de $50 \mathrm{~kg} \mathrm{P}_{2} \mathrm{O}_{5} / \mathrm{ha}$ e $200 \mathrm{~kg} \mathrm{~K} 2 \mathrm{O} / \mathrm{ha}$ (CANTARUTTI et al., 1999), utilizando como fontes o superfosfato simples e o cloreto de potássio, respectivamente, sendo as mesmas doses para os dois anos de avaliação (2002/2003 e 2003/2004). O superfosfato simples foi distribuído em única aplicação no início da estação chuvosa, em ambos os anos. O cloreto de potássio foi distribuído em duas aplicações após os cortes do capimelefante no período das águas, realizadas juntamente com a adubação nitrogenada, em ambos os anos de avaliação.

$\mathrm{O}$ delineamento experimental foi em blocos casualizados, com dezessete tratamentos e três repetições. Os tratamentos foram arranjados em esquema fatorial $4 \times 4+1$, sendo quatro doses do herbicida glyphosate $(0,720,1440 \mathrm{e}$ $2160 \mathrm{~g} / \mathrm{ha} /$ aplicação), quatro doses de nitrogênio $(0,75,150 \mathrm{e}$ $225 \mathrm{~kg} \mathrm{~N} / \mathrm{ha} / \mathrm{ano}$ ) e um tratamento adicional (testemunha com capina). As doses de nitrogênio e do herbicida glyphosate foram estabelecidas conforme recomendações de Cantarutti et al. (1999) e Rodrigues \& Almeida (1995), respectivamente. 
TABELA 1 - Caracterização química do solo $(0-10 \mathrm{~cm}) *$ da capineira nova no primeiro (2002-2003) e segundo anos de avaliação (2003-2004).

\begin{tabular}{|c|c|c|c|c|}
\hline \multirow{2}{*}{ Atributos } & \multicolumn{2}{|c|}{ Primeiro Ano } & \multicolumn{2}{|c|}{ Segundo Ano } \\
\hline & Valores & Interpretação & Valores & Interpretação \\
\hline pH em água & 6,4 & Acidez Fraca & 6,1 & Acidez Fraca \\
\hline $\mathrm{P}\left(\mathrm{mg} / \mathrm{dm}^{3}\right)$ & 0,6 & Muito Baixo & 0,9 & Muito Baixo \\
\hline $\mathrm{K}^{+}\left(\mathrm{mg} / \mathrm{dm}^{3}\right)$ & 40,0 & Baixo & 27,0 & Baixo \\
\hline $\mathrm{Ca}^{2+}\left(\mathrm{cmol}_{\mathrm{c}} / \mathrm{dm}^{3}\right)$ & 2,9 & Bom & 2,6 & Bom \\
\hline $\mathrm{Mg}^{2+}\left(\mathrm{cmol}_{\mathrm{c}} / \mathrm{dm}^{3}\right)$ & 1,5 & Bom & 1,0 & Bom \\
\hline $\mathrm{Al}^{3+}\left(\mathrm{cmol}_{\mathrm{c}} / \mathrm{dm}^{3}\right)$ & 0,1 & Muito Baixo & 0,0 & Muito Baixo \\
\hline $\mathrm{H}^{+}+\mathrm{Al}^{3+}\left(\mathrm{cmol}_{\mathrm{C}} / \mathrm{dm}^{3}\right)$ & 2,9 & Médio & 2,9 & Médio \\
\hline $\mathrm{SB}\left(\mathrm{cmol}_{\mathrm{c}} / \mathrm{dm}^{3}\right)$ & 4,5 & Bom & 3,7 & Bom \\
\hline $\mathrm{t}\left(\mathrm{cmol}_{\mathrm{c}} / \mathrm{dm}^{3}\right)$ & 4,6 & Médio & 3,7 & Médio \\
\hline $\mathrm{T}\left(\mathrm{cmol}_{\mathrm{c}} / \mathrm{dm}^{3}\right)$ & 7,4 & Médio & 6,6 & Médio \\
\hline $\mathrm{m}(\%)$ & 2,0 & Muito Baixo & 0,0 & Muito Baixo \\
\hline $\mathrm{V}(\%)$ & 60,9 & Bom & 55,9 & Médio \\
\hline P-rem (mg/L) & 9,1 & -- & 10,9 & -- \\
\hline
\end{tabular}

*Análises realizadas no Departamento de Solos de UFLA, segundo a metodologia da Embrapa (1997).

As parcelas foram constituídas de quatro fileiras de capim-elefante de 5,0 $\mathrm{m}$ de comprimento, espaçadas entre si de $1,0 \mathrm{~m}$, perfazendo área total de $20,0 \mathrm{~m}^{2}$. A área útil constituiu-se de duas fileiras centrais, descontandose $0,50 \mathrm{~m}$ nas extremidades, perfazendo $8,0 \mathrm{~m}^{2}$.

O corte de uniformização foi feito manualmente em 01/12/2002, com uso do podão. As aplicações de nitrogênio e do herbicida glyphosate foram feitas imediatamente após os cortes no período das águas, em ambos os anos (dezembro/2002; fevereiro/2003; novembro/2003; fevereiro/ 2004). A adubação nitrogenada foi aplicada juntamente com a potássica, próximo às fileiras do capim-elefante. As aplicações do herbicida glyphosate foram realizadas com pulverizador costal à pressão constante $\left(\mathrm{CO}_{2}\right)$ de $2,8 \mathrm{~kg} /$ $\mathrm{cm}^{2}$, munido de aplicador tipo "Chapéu de Napoleão", com bico leque 110.02 e volume de aplicação de calda equivalente a $400 \mathrm{~L} / \mathrm{ha}$. As aplicações foram efetuadas na ausência de vento, sempre no final da tarde. Devido à não seletividade, a aplicação do herbicida glyphosate foi feita quando se eliminou completamente a área foliar do capim-elefante, ou seja, imediatamente após o corte (rente ao solo), de modo a atingir apenas a parte aérea do capim-braquiária.

As características avaliadas no capim-elefante foram número de perfilhos basais e produção de matéria seca (MS). O número de perfilhos basais foi avaliado por meio da contagem de perfilhos na área útil, sendo os valores caracterizados em número de perfilhos basais $/ \mathrm{m}^{2}$. A produção de MS foi calculada a partir da forragem verde colhida na área útil, corrigindo-se pelo seu respectivo teor de MS (AOAC, 1990).

As características avaliadas no capim-braquiária foram produção de MS e tamanho do banco de sementes. A produção de MS das parcelas foi calculada a partir da forragem verde, colhida no quadrado de $1,0 \mathrm{~m}^{2}$, corrigindose pelo seu respectivo teor de MS (AOAC, 1990).

O tamanho do banco de sementes foi determinado conforme metodologia descrita em Monquero \& Christoffoleti (2003). As amostragens de solo foram feitas com trado caneco de 3,8 cm de diâmetro na profundidade de $0-10 \mathrm{~cm}$, coletandose cinco amostras por parcela no início (dezembro/2002) e final do experimento (abril/2004), sendo posteriormente secas em estufa de circulação forçada a $35^{\circ} \mathrm{C}$ por 12 horas. Cerca de $100 \mathrm{~g}$ de solo de cada amostra e $100 \mathrm{~mL}$ de solução dispersante (carbonato de potássio) foram colocados em garrafas e centrifugadas por 15 minutos a $10.000 \mathrm{rpm}$, separando-se a matéria mineral e orgânica (sobrenadante). Os sobrenadantes foram passados em peneira de 35 mesh de malha e o material retido foi lavado em água corrente e colocado em placa de petri revestida com papel de filtro, sendo secas em estufa de circulação forçada a $35^{\circ} \mathrm{C}$ por 12 horas. Em seguida, realizou- 
se separação e posterior contagem das sementes de $B$. decumbens. A densidade do solo, determinada pelo método do anel volumétrico (EMBRAPA, 1997), foi de $1,24 \mathrm{~g} / \mathrm{cm}^{3}$. O número provável de sementes/ha (NPS) foi calculado da seguinte forma: NPS $=($ sementes extraídas/amostra $\times 1.240 .000$ $\mathrm{kg}) /($ peso da amostra em $\mathrm{kg}$ ).

Os dados obtidos foram submetidos à análise de variância e regressão, conforme metodologia descrita por Ribeiro Junior (2001), utilizando-se o software SAEG.

\section{RESULTADOS E DISCUSSÃO}

\section{Produção de matéria seca e perfilhamento do capim- elefante}

Observou-se efeito linear $(\mathrm{P}<0,01)$ do herbicida glyphosate $(\mathrm{G})$, nitrogênio $(\mathrm{N})$ e interação $(\mathrm{GxN})$ sobre a produção de MS do capim-elefante em ambos os anos. Na ausência do herbicida e de nitrogênio, a produção alcançada foi de $3,02\left(1^{\circ}\right.$ ano) e $3,87 \mathrm{t} / \mathrm{ha}\left(2^{\circ}\right.$ ano) (Figuras 1a e 1b). Entretanto, na combinação $2160 \mathrm{~g}$ glyphosate/ha/ aplicação e $225 \mathrm{~kg} \mathrm{~N} / \mathrm{ha} / \mathrm{ano}$, os rendimentos foram de 22,95 ( $1^{\circ}$ ano) e $27,92 \mathrm{t} / \mathrm{ha}\left(2^{\circ}\right.$ ano), correspondendo a incrementos de 657 e $621 \%$, respectivamente (Figuras 1a e 1b).

A menor produção de matéria seca, na ausência do herbicida glyphosate e nitrogênio, em ambos os anos, certamente ocorreu devido à ação direta da competição pelos elementos vitais (água, luz e nutrientes) que se estabeleceu com o capim-braquiária. Assim, a aplicação do herbicida glyphosate possivelmente proporcionou a eliminação de plântulas e plantas de $B$. decumbens, reduzindo a competição com o capim-elefante. $\mathrm{O}$ coeficiente de correlação entre produção de MS do capim-elefante e produção de MS do capim-braquiária foi de $-0,79^{* *}$, indicando que à medida que diminuiu a produção de MS do capim-braquiária ocorreu um aumento na produção de MS do capim-elefante. Kuva et al. (2001) observaram correlação negativa entre a produção de massa de $B$. decumbens e a produção de cana-de-açúcar, concluindo que a cada $3,70 \mathrm{~g} / \mathrm{m}^{2}$ de MS acumulada do capimbraquiária havia uma estimativa de redução na produtividade da cana-de-açúcar da ordem de 1,0 t/ha.

À medida que aumentou a quantidade de nitrogênio para uma mesma dose de glyphosate, observaram-se incrementos na produção de MS do capim-elefante. Isto porque, a adubação nitrogenada estimula mais rapidamente $o$ crescimento do capim-elefante, sendo possível colheitas mais freqüentes de forragem mais digestível, além de promover o sombreamento mais rápido nas entrelinhas, reduzindo a infestação do capim-braquiária. Ribeiro (1995) relatou produção de 14,22 e 13,66 t MS/ha, quando o capim-elefante cv. Anão foi cortado ao atingir 80 a $120 \mathrm{~cm}$ de altura e recebeu aplicação de $300 \mathrm{~kg} \mathrm{~N} / \mathrm{ha}$. Martello (1999) verificou que a aplicação do nitrogênio no final do período das águas (março), além de aumentar a produção de MS do capim-elefante cv. Guaçu nos três primeiros cortes (maio, setembro e novembro) e no total anual, aumentou de 27 para $34 \%$ a proporção de forragem produzida no período das secas, quando se elevou as doses de nitrogênio de 60 para $240 \mathrm{~kg} / \mathrm{ha}$.

A eficiência de resposta ao nitrogênio, relativa às produções observadas em dois anos de avaliação, variou de 25,7 a $60,3 \mathrm{~kg} \mathrm{MS} / \mathrm{kg}$ N e de 29,7 a 70,8 $\mathrm{kg} \mathrm{MS} / \mathrm{kg} \mathrm{N}$, respectivamente, e equivalem às relatadas por VicenteChandler et al. (1959), que encontraram, para capim-elefante cv. Napier, eficiências de 47,3 a 53,9 kg MS/kg N, respectivamente, para as doses de 224 e $448 \mathrm{~kg} / \mathrm{ha} / \mathrm{ano}$. Paciullo (1997), avaliando o capim-elefante cv. Anão, encontrou eficiências de resposta de 8,5 a 20,1 kg MS/ $/ \mathrm{kg} \mathrm{N}$, para as plantas cortadas com $80 \mathrm{~cm}$ de altura, e de 11,0 a 20,4 $\mathrm{kg}$ MS/kg N, para as plantas cortadas com $120 \mathrm{~cm}$ de altura.

$\mathrm{O}$ perfilhamento auxilia o estabelecimento e a perenidade das gramíneas forrageiras, assegura maior proteção ao solo contra a ação dos fatores do ambiente, bem como controla a presença de plantas invasoras através do sombreamento. Observou-se efeito linear $(\mathrm{P}<0,01)$ do herbicida glyphosate $(\mathrm{G})$ e nitrogênio $(\mathrm{N})$ sobre o número médio de perfilhos basais produzidos em ambos os anos. $\mathrm{Na}$ ausência do herbicida e de nitrogênio, a produção média foi de $8,42\left(1^{\circ}\right.$ ano) e 6,04 perfilhos basais $/ \mathrm{m}^{2}$ ( $2^{\circ}$ ano) (Figuras 1c e 1d). Entretanto, na combinação $2160 \mathrm{~g}$ glyphosate/ha/ aplicação e $225 \mathrm{~kg} \mathrm{~N} / \mathrm{ha} / \mathrm{ano}$, a produção média foi de 27,16 ( $1^{\circ}$ ano) e 29,43 perfilhos basais $/ \mathrm{m}^{2}$ ( $2^{\circ}$ ano), correspondendo a incrementos de 222 e $387 \%$, respectivamente (Figuras 1c e 1d). Lira et al. (1998) encontraram para sete novos clones de capim-elefante média de 24 perfilhos basais $/ \mathrm{m}^{2}$.

A aplicação do herbicida glyphosate eliminou plântulas e plantas de capim-braquiária, permitindo maior penetração de luz até a base das touceiras de capimelefante, estimulando o perfilhamento. $O$ coeficiente de correlação entre número médio de perfilhos basais produzidos pelo capim-elefante e a produção de MS do capim-braquiária foi de $-0,73^{* *}$. Isto representa que à medida que diminuiu a produção de MS do capim-braquiária ocorreu aumento no número médio de perfilhos basais produzidos pelo capim-elefante. Esse resultado deve-se ao fato de que a intensidade de luz pode ser considerada como o fator ambiental mais limitante na dinâmica do perfilhamento em gramíneas, posto que na grande maioria das espécies as maiores intensidades luminosas favorecem o perfilhamento (LANGER, 1972). O nível de radiação incidente é, assim, um fator ambiental de importância; em altos níveis, a radiação solar estimula o perfilhamento e, em baixos níveis, o crescimento das gemas axilares e basais é reduzido (PEDREIRA et al., 2001).

Ciênc. agrotec., Lavras, v. 30, n. 5, p. 977-987, set./out., 2006 
$\hat{\mathbf{Y}} \mathbf{a}=3,029000+0,002949 \mathrm{G}^{* *}+0,025696 \mathrm{~N}^{* *}+0,000016 \mathrm{GN} \mathrm{N}^{* *}\left(\mathbf{R}^{2}=0,9831\right)$

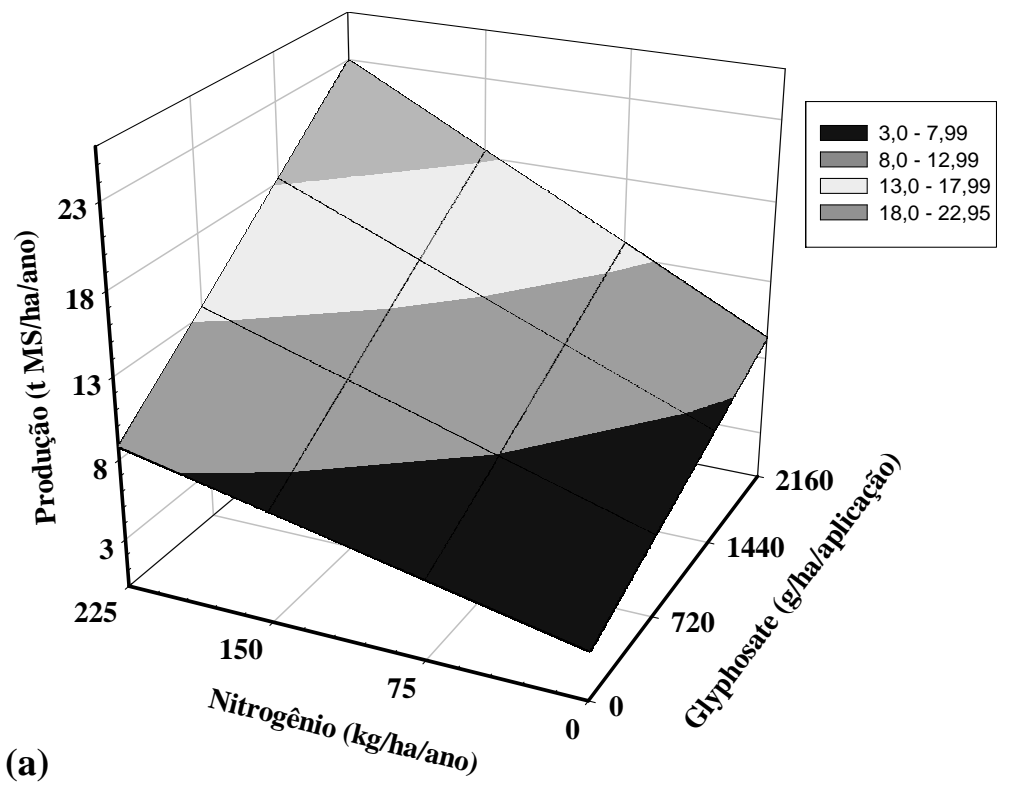

$\hat{\mathbf{Y}} \mathbf{b}=3,866224+0,003763 \mathrm{G}^{* *}+0,029725 \mathrm{~N}^{* *}+0,000019 \mathrm{GN} \mathrm{N}^{* *}\left(\mathrm{R}^{2}=0,9767\right)$

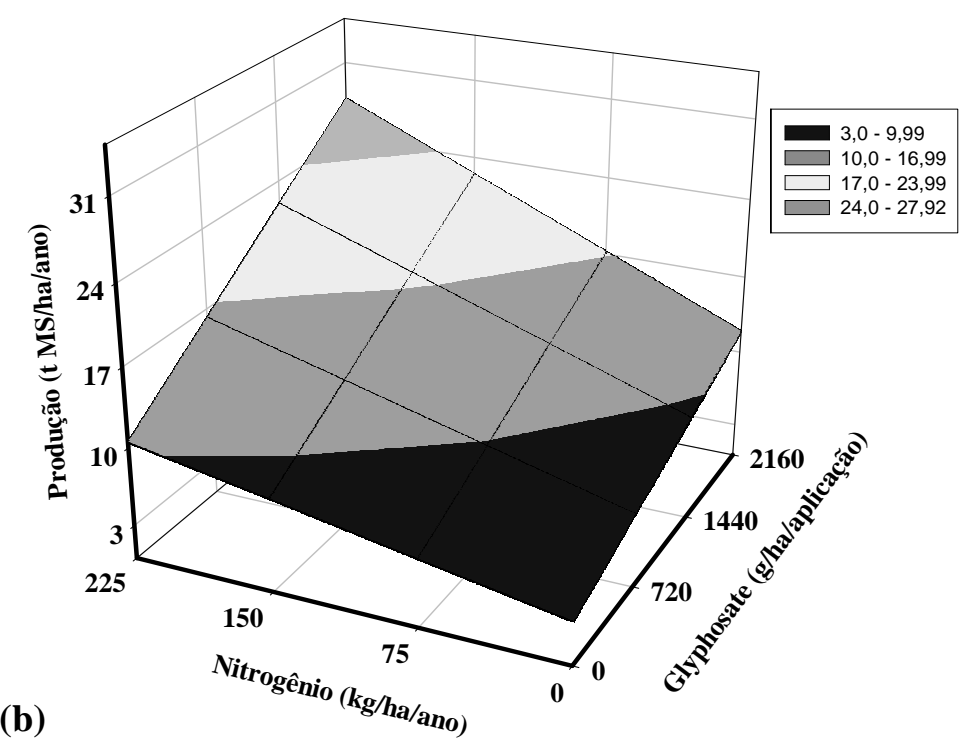

Ciênc. agrotec., Lavras, v. 30, n. 5, p. 977-987, set./out., 2006 


$$
\hat{\mathbf{Y}} \mathrm{c}=8,4187+0,0033 \mathrm{G}^{* *}+0,0516 \mathrm{~N}^{* *}\left(\mathrm{R}^{2}=0,9978\right)
$$

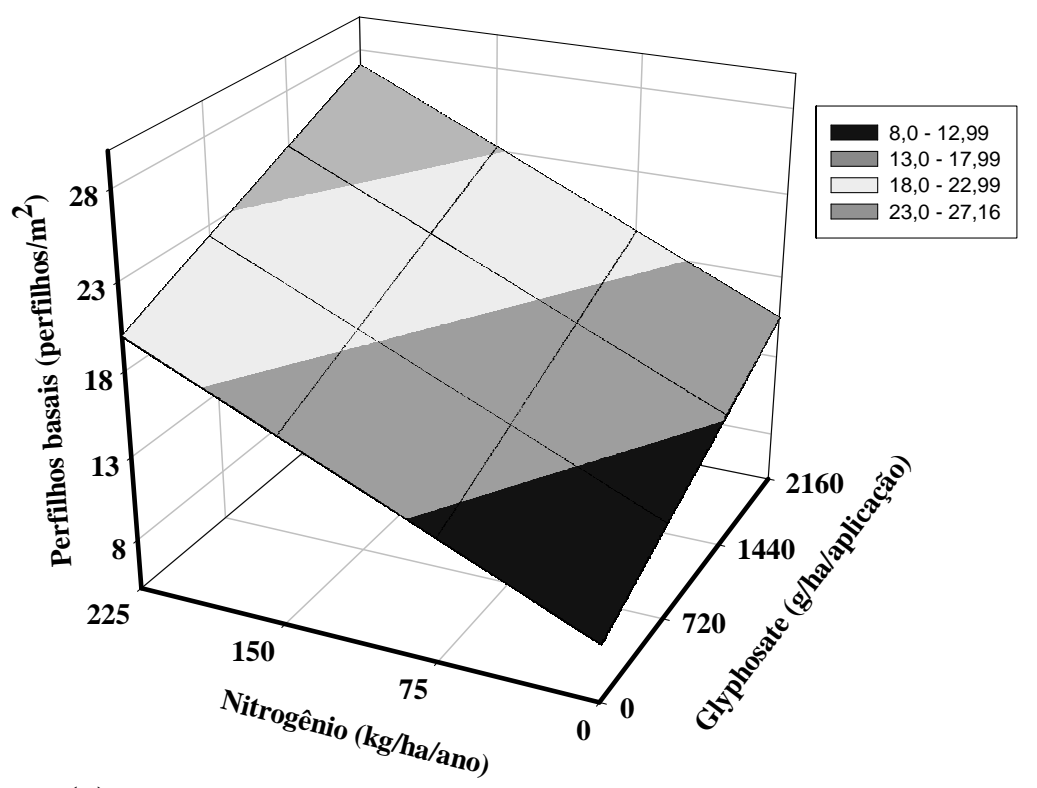

(c)

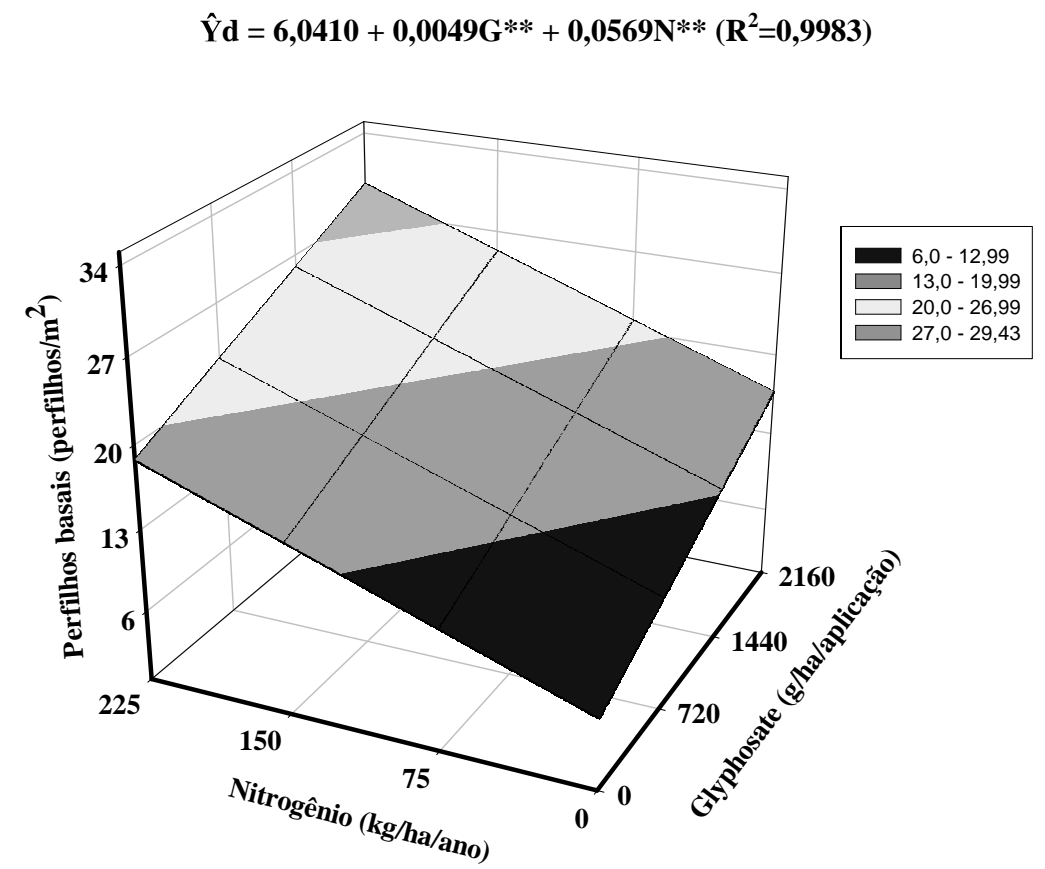

(d)

Ciênc. agrotec., Lavras, v. 30, n. 5, p. 977-987, set./out., 2006 
$\hat{\mathbf{Y}} \mathrm{e}=4,32951000-0,00255346 \mathrm{G}^{* *}+0,00000027 \mathrm{G}^{2 * *}-0,00638045 \mathrm{~N}^{* *}+0,00000307 \mathrm{GN}^{* *}\left(\mathbf{R}^{2}=0,9914\right)$

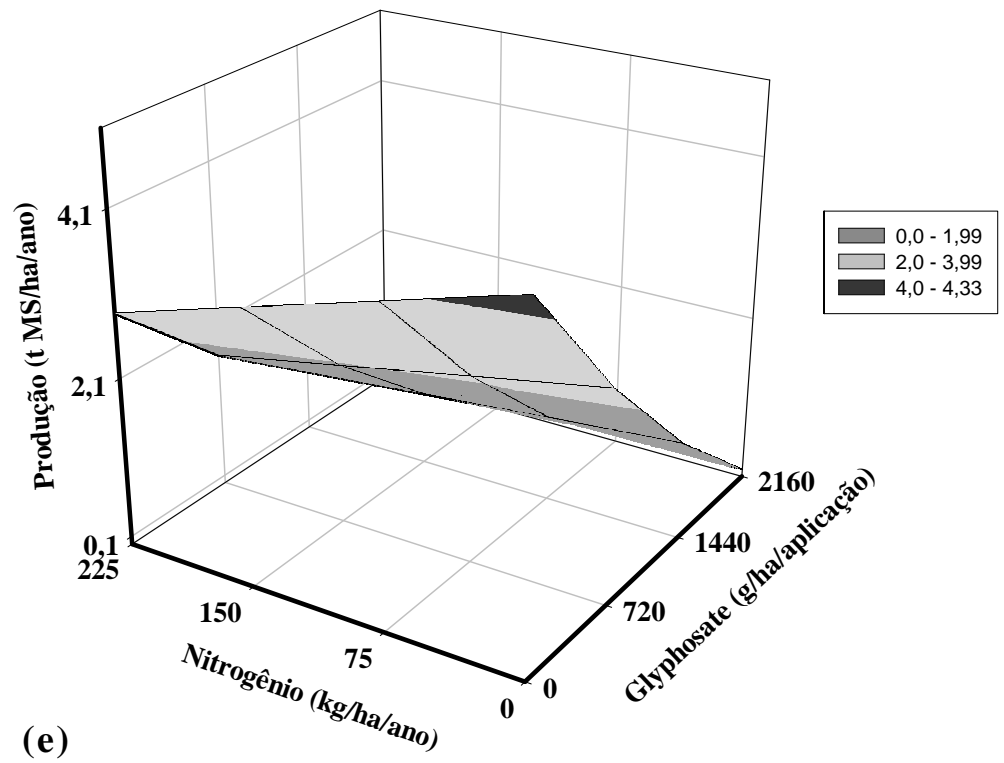

$\hat{Y} f=4,36450000-0,00308611 G^{* *}+0,00000050 G^{2 * *}-0,00524445 N^{* *}+0,00000279 G N * *\left(R^{2}=0,9904\right)$

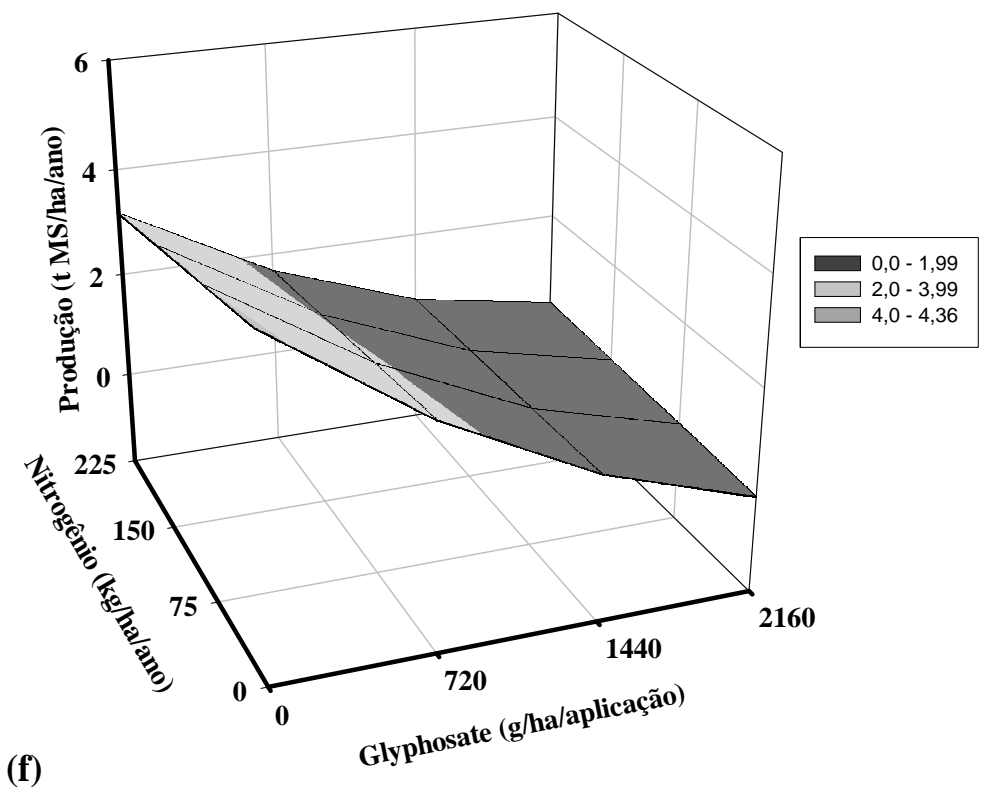

Ciênc. agrotec., Lavras, v. 30, n. 5, p. 977-987, set./out., 2006 


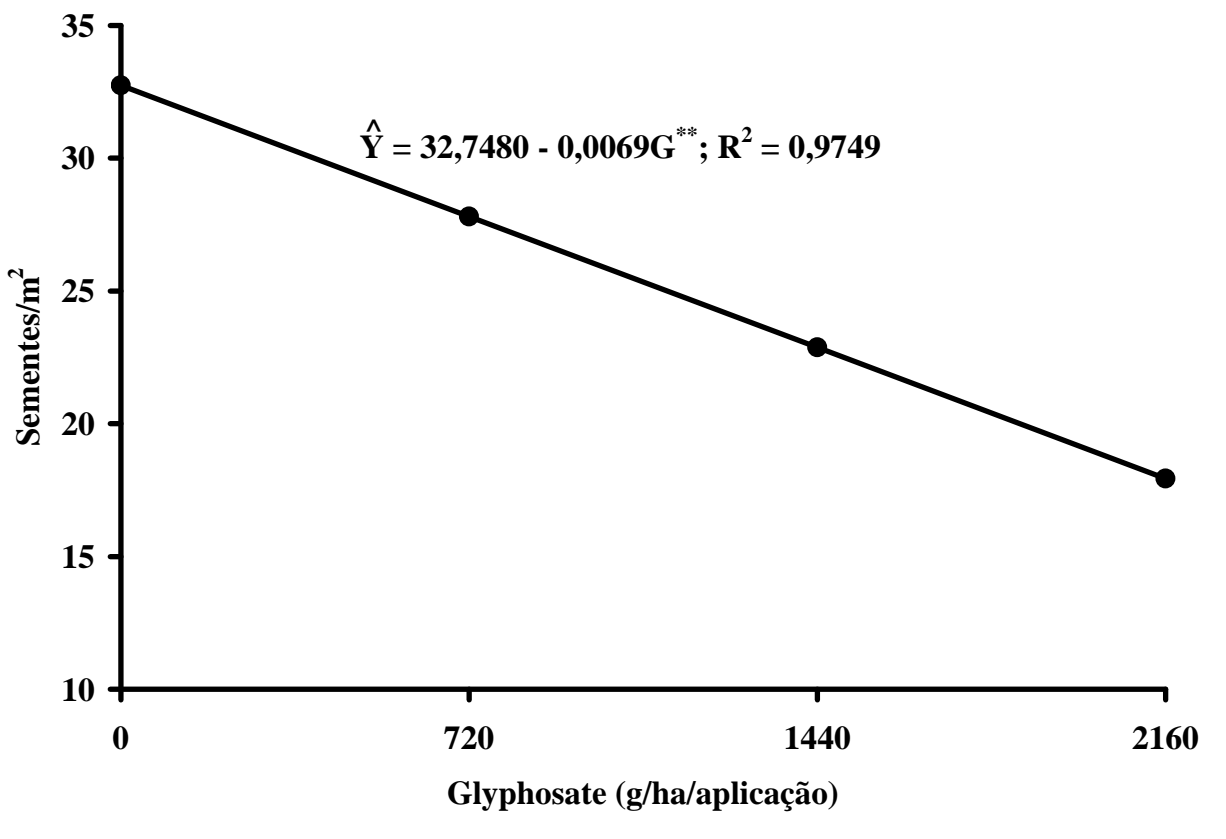

FIGURA 1 - Produção de matéria seca do capim-elefante ( $t / h a)$ no primeiro (a) e segundo ano (b); número de perfilhos basais produzidos pelo capim-elefante (perfilhos $/ \mathrm{m}^{2}$ ) no primeiro (c) e segundo ano (d); Produção de matéria seca do capim-braquiária (t/ ha) no primeiro (e) e segundo ano (f) em função das doses de nitrogênio e glyphosate; tamanho do banco de sementes de capimbraquiária (sementes $/ \mathrm{m}^{2}$ ) no final do experimento em função das doses de glyphosate.

Além do efeito da luz, o nitrogênio também estimulou a produção de perfilhos basais pelo capim-elefante. À medida que aumentou a quantidade de nitrogênio para uma mesma dose de glyphosate, observaram-se incrementos no número médio de perfilhos basais produzidos. Dantas et al. (2002) também verificaram aumento de $83,4 \%$ no número de perfilhos totais produzidos pelo capim-elefante cv. Anão quando foram aplicados $50 \mathrm{~kg} \mathrm{~N} / \mathrm{ha}\left(30,64\right.$ perfilhos totais $\left./ \mathrm{m}^{2}\right) \mathrm{em}$ Argissolo. Para Neossolo, as melhores respostas só ocorreram com a aplicação de $100(18,92)$ e $200 \mathrm{~kg} \mathrm{~N} / \mathrm{ha}$ $\left(20,14\right.$ perfilhos totais $\left./ \mathrm{m}^{2}\right)$. Os autores concluíram que o número de perfilhos caracteriza a capacidade da gramínea em aumentar o índice de área foliar, ocupando maior área e, conseqüentemente, diminuindo a concorrência com as plantas daninhas.

O coeficiente de correlação linear entre o número médio de perfilhos produzidos e a produção de MS do capim-elefante foi de $0,96^{* *}$, indicando que à medida que aumentou o número médio de perfilhos basais produzidos ocorreu um aumento na produção de MS do capim-elefante. Silva et al. (1996) também demonstraram o efeito estimulador do nitrogênio sobre a formação de novos perfilhos, fazendo com que, se aplicado na época certa, seja capaz de promover a formação de número maior de perfilhos por unidade de área em capim-elefante.

\section{Produção de matéria seca e tamanho do banco de sementes do capim-braquiária}

Observou-se efeito linear $(\mathrm{P}<0,01)$ do herbicida glyphosate $(\mathrm{G})$, nitrogênio $(\mathrm{N})$ e interação $(\mathrm{GxN})$ e efeito quadrático $(\mathrm{P}<0,01)$ do herbicida glyphosate sobre a produção de MS do capim-braquiária em ambos os anos. $\mathrm{Na}$ ausência do herbicida e de nitrogênio, a produção foi de 4,33 ( $1^{\circ}$ ano) e 4,36 t/ha ( $2^{\circ}$ ano) (Figuras 1e e $\left.1 \mathrm{f}\right)$. Entretanto, na combinação $2160 \mathrm{~g}$ glyphosate/ha/aplicação e $225 \mathrm{~kg} \mathrm{~N} / \mathrm{ha} / \mathrm{ano}$, os rendimentos foram de 0,13 ( $1^{\circ}$ ano) e 0,21 t/ha ( $2^{\circ}$ ano), proporcionando uma redução na produção de MS capim-braquiária da ordem de 97,00 e $95,19 \%$, respectivamente (Figuras 1e e 1f). Por outro lado, verificou-se produção de $2,89\left(1^{\circ}\right.$. ano) e $3,18 \mathrm{t} /$ ha $\left(2^{\circ}\right.$. ano) com aplicação de $225 \mathrm{~kg} \mathrm{~N} / \mathrm{ha} /$ ano e ausência do glyphosate. Assim, a associação de métodos de controle (químico e cultural) constitui uma boa opção para redução da infestação de B. decumbens em capineiras estabelecidas. 
O herbicida glyphosate propiciou controle das plantas de capim-braquiária provenientes de propagação vegetativa e sexuada, além da aplicação ser feita em jato dirigido nas entrelinhas do capim-elefante. Isto permitiu uma redução no gasto com a aplicação do herbicida, visto que a utilização de capineiras é feita em pequenas áreas (1 a 5 ha). O herbicida glyphosate, na dose de $1440 \mathrm{~g} / \mathrm{ha}$, também exerceu eficiente controle de Brachiaria spp. em capineiras estabelecidas na Região Sul de Minas Gerais (EVANGELISTA et al., 2000).

Apesar do controle do capim-braquiária no primeiro ano, ocorreu reinfestação $\left(2^{\circ}\right.$ ano) devido à presença de grande quantidade de sementes próximas à superfície do solo (banco de sementes). $O$ coeficiente de correlação entre a produção de MS do capim-braquiária e o tamanho do banco de sementes de capim-braquiária no solo foi de $0,90^{* *}$, demonstrando que à medida que aumentou o tamanho do banco de sementes ocorreu um aumento na produção de MS do capim-braquiária.

Nas parcelas em que se aplicou o herbicida glyphosate, o capim-braquiária estava no estádio de préflorescimento, evitando-se, portanto, a produção de sementes e prevenindo aumento do banco de sementes. Schweizer \& Zimdahl (1984) concluíram que, quando a produção de sementes de plantas daninhas foi prevenida ou minimizada, a maioria das sementes indesejáveis viáveis foi eliminada do banco de sementes dentro de um a quatro anos, independentemente da prática agronômica empregada (tipos de preparo do solo, uso de herbicidas etc...).

No início do experimento (novembro/2002), o tamanho do banco de sementes de capim-braquiária era de 882,87 sementes $/ \mathrm{m}^{2}$. Macedo (1995), avaliando pastagens de $B$. decumbens com 10 a 15 anos de idade, encontrou 1000 sementes puras viáveis $(\mathrm{SPV}) / \mathrm{m}^{2}$, nos primeiros $5 \mathrm{~cm}$ da camada de solo, o que equivale a $50 \mathrm{~kg}$ de SPV/ha.

Em avaliação no final do experimento (abril/2004), observou-se efeito linear $(\mathrm{P}<0,01)$ do glyphosate $(\mathrm{G})$ sobre o tamanho do banco de sementes de capim-braquiária. À medida que se aumentaram doses do herbicida glyphosate, verificouse um decréscimo linear no número de sementes de capimbraquiária presentes no banco de sementes (Figuras 1g).

$\mathrm{Na}$ ausência do herbicida glyphosate, o tamanho médio do banco de sementes aumentou em 21,37\% (1071,56 sementes $/ \mathrm{m}^{2}$ ) em relação ao início do experimento. Este acréscimo provavelmente será o responsável por reinfestações futuras do capim-braquiária na capineira, pois um dos principais mecanismos de sobrevivência das plantas daninhas é a alta produção de sementes. Monquero \& Christoffoleti (2003), avaliando a dinâmica de bancos de sementes em áreas com aplicação freqüente do herbicida glyphosate, verificaram aumento do banco de sementes de Amaranthus hybridus L. de 3,1 bilhões de sementes/ha (início do experimento) para 6,8 bilhões de sementes/ha (após dois anos), nas parcelas sem aplicação do herbicida.

A aplicação de $2160 \mathrm{~g} / \mathrm{ha}$ de glyphosate proporcionou uma redução no tamanho médio do banco de sementes da ordem de $64 \%\left(317,26\right.$ sementes $\left./ \mathrm{m}^{2}\right)$, indicando que a aplicação repetitiva do herbicida provocou alteração na dinâmica do BS do capim-braquiária. Monquero \& Christoffoletti (2003) observaram que o tamanho do banco de sementes de Amaranthus hybridus foi decrescendo após dois anos de aplicação repetitiva do glyphosate, sendo que, na maior dose, os autores encontraram 140 milhões de sementes/ha em comparação com a testemunha (sem glyphosate), 6,8 bilhões de sementes/ha.

O decréscimo de bancos de sementes no solo varia em função de espécie, dormência, condições ambientais, presença de predadores e microrganismos. A principal forma de decréscimo de bancos de sementes é por meio da germinação. A proximidade da superfície do solo aumentou a exposição de sementes de $B$. decumbens a fatores como luz, alternância de temperatura e umidade, os quais normalmente promovem a germinação. O estímulo à germinação aliado a aplicação de glyphosate na fase de pré-florescimento impediu a nova produção de sementes de capim-braquiária, reduzindo, conseqüentemente, o banco de sementes no solo, previnindo futuras reinfestações.

\section{CONCLUSÕES}

A associação entre o herbicida glyphosate (2160 g/ ha/aplicação) e nitrogênio ( $225 \mathrm{~kg} / \mathrm{ha} / \mathrm{ano})$ foi eficiente no controle de capim-braquiária em capineiras estabelecidas.

A aplicação do herbicida glyphosate $(2160 \mathrm{~g} / \mathrm{ha} /$ aplicação) reduziu o tamanho do banco de sementes de capim-braquiária no solo em $64 \%$.

\section{REFERÊNCIAS BIBLIOGRÁFICAS}

ASSOCIATION OF OFFICIAL AGRICULTURAL CHEMISTS. Official methods of analisys. 15. ed. Virginia, 1990. v. 1, 684 p.

CANTARUTTI, R. B.; MARTINS, C. E.; CARVALHO, M. M.; FONSECA, D. M.; ARRUDA, M. L.; VILELA, H.; OLIVEIRA, F. T. T. Pastagens. In: RIBEIRO, A. C.; GUIMARÃES, P. T. C.; ALVAREZ, V. H. Recomendações para uso de corretivos e fertilizantes em Minas Gerais: $5^{\mathrm{a}}$ aproximação. Viçosa: UFV, 1999. p. 332-341. 
CASTRO NETO, P.; SEDIYAMA, G. C.; VILELA, E. A. Probabilidade de ocorrência de períodos secos em Lavras, MG. Revista Ciência e Prática, Lavras, v. 4, n. 1, p. 46-55, jan./jun. 1980.

CORSI, M. Adubação nitrogenada das pastagens. In: PEIXOTO, A. M.; MOURA, J. C. de; FARIA, V. P. de. Pastagens: fundamentos da exploração racional. Piracicaba: ESALQ, 1994. p. 109-132.

DANTAS, J. A.; BEZERRA NETO, E.; AGUIAR, E. M. Efeito da adubação nitrogenada no desenvolvimento vegetativo do capim-elefante cv. Mott em dois tipos de solos. In: REUNIÃO ANUAL DA SOCIEDADE BRASILEIRA DE ZOOTECNIA, 39., 2002, Recife. Anais...Recife: SBZ, 2002. CD-ROM.

EMPRESA BRASILEIRA DE PESQUISA AGROPECUÁRIA. Serviço Nacional de Levantamento e Conservação de Solos. Manual de métodos de análises de solo. Rio de Janeiro, 1997. 212 p.

EVANGELISTA, A. R.; GONÇALVES, C. C. M.; VIEIRA NETO, J. C.; ISHIDA, E. T. Avaliação de herbicidas no manejo da capineira. In: REUNIÃO ANUAL DA SOCIEDADE BRASILEIRA DE ZOOTECNIA, 37., 2000, Viçosa. Anais... Viçosa: SBZ, 2000. CD-ROM.

KUVA, M. A.; GRAVENA, R.; PITELli, R. A.; CHRISTOFFOLETI, P. J.; ALVES, P. L. C. A. Períodos de interferência das plantas daninhas na cultura da cana-deaçúcar: II capim-braquiária (Brachiaria decumbens). Planta Daninha, Viçosa, v. 19, n. 3, p. 323-330, 2001.

LANGER, T. H. M. How grasses grow. London: E. Arnold, 1972. $60 \mathrm{p}$.

LIRA, M. A.; DUBEUX JUNIOR, J. C. B.; OLIVEIRA, C. F. Competição de cultivares de capim-elefante (Pennisetum purpurem Schum.) e de seus híbridos com milheto (Pennisetum americanum (L.) Leeke), sob pastejo. In: REUNIÃO ANUAL DA SOCIEDADE BRASILEIRA DE ZOOTECNIA, 35., 1998, Botucatu. Anais... Botucatu: SBZ, 1998. p. 421-423.

LOURENÇO, A. J.; SARTINI, H. J.; SANTA-MARIA, M.; ROCHA, G. L. Estudo comparativo entre três níveis de fertilização nitrogenada e consorciada com leguminosas em pastagens de capim-elefante (Pennisetum purpureum cv. Napier) na determinação da capacidade de suporte. Boletim da Indústria Animal, Nova Odessa, v. 35, n. 1, p. 69-80, jan./jun. 1978.
MACEDO, M. C. M. Acabar com as braquiárias dá trabalho. Campo Grande: EMBRAPA-CNPGC, 1995. 4 p. (CNPGC Divulga, 5).

MARTELLO, V. P. Doses de nitrogênio para maximização da produção do capim-elefante cv. Guaçu no período das secas. 1999. 46 f. Dissertação (Mestrado em Ciência Animal e Pastagens) - Escola Superior de Agricultura Luiz de Queiroz, Universidade de São Paulo, Piracicaba, 1999.

MONQUERO, P. A.; CHRISTOFFOLETI, P. J. Dinâmica do banco de sementes em áreas com aplicação freqüente do herbicida glyphosate. Planta Daninha, Viçosa, v. 21, n. 1, p. 63-69, 2003.

PACIULLO, D. S. C. Produtividade e valor nutritivo do capim-elefante Anão (Pennisetum purpureum Schum. cv. Mott) ao atingir 80 e $120 \mathrm{~cm}$ de altura sob diferentes doses de nitrogênio. 1997. 60 p. Dissertação (Mestrado em Zootecnia) - Universidade Federal de Viçosa, Viçosa, 1997.

PEDREIRA, C. G. S.; MELLO, A. C. L.; OTANI, L. O processo de produção de forragem. In: REUNIÃO ANUAL DA SOCIEDADE BRASILEIRA DE ZOOTECNIA, 38., 2001, Piracicaba. Anais... Piracicaba: SBZ, 2001. CD-ROM.

RIBEIRO, K. G. Rendimento forrageiro e valor nutritivo do capim-elefante Anão, sob cinco doses de nitrogênio, ao atingir 80 e 120 cm de altura. 1995. 60 f. Dissertação (Mestrado em Zootecnia) - Universidade Federal de Viçosa, Viçosa, 1995.

RIBEIRO JÚNIOR, J. I. Análises estatísticas no SAEG. Viçosa: UFV, 2001. 301 p.

RODRIGUES, B. N.; ALMEIDA, F. S. Guia de herbicidas. Londrina: Ed. dos Autores, 1995. 657 p.

RODRIGUES, L. R. de A.; REIS, R. A. Estabelecimento de outras forrageiras em áreas de Brachiaria spp. In: SIMPÓSIO SOBRE MANEJO DA PASTAGEM, 11., 1994, Piracicaba. Anais... Piracicaba: FEALQ, 1994. p. 299-325.

RODRIGUES, L. R. de A.; RODRIGUES, T. J. D. Estabelecimento de capins do gênero Cynodon em áreas de Brachiaria spp. In: WORKSHOP SOBRE O POTENCIAL FORRAGEIRO DO GÊNERO CYNODON, 1996, Juiz de Fora. Anais... Juiz de Fora: EMBRAPA-CNPGL, 1996. p. 9-21.

Ciênc. agrotec., Lavras, v. 30, n. 5, p. 977-987, set./out., 2006 
SANTOS, F. A. P. Manejo de pastagens de capimelefante. In: PEIXOTO, A. M.; MOURA, J. C. de; FARIA, V. P. de. Volumosos para bovinos. Piracicaba: FEALQ, 1995. p. 1-20.

SCHWEIZER, E. E.; ZIMDAHL, R. L. Weed seed decline in irrigated soil after six years of continuous corn (Zea mays) and herbicides. Weed Science, Champaign, v. 32, n. 1, p. 76-83, Jan./Feb. 1984.

SILVA, S. C.; CORSI, M.; FARIA, V. P. Correção do solo e adubação de pastagens de capim-elefante. In: PEIXOTO, A. M.; MOURA, J. C.; FARIA, V. P. Pastagens de capim-elefante: utilização intensiva. Piracicaba: FEALQ, 1996. p. 29-50.

SIMPSON, R. L.; LECK, M. A.; PARKER, V. T. Seed banks: general concepts and methodological issues. In: LECK, M. A.; PARKER, V. P.; SIMPSON, R. L. Ecology of soil seed banks. New York: Academic, 1989. p. 69-86.

VICENTE-CHANDLER, J.; SILVA, S.; FIGARELLA, J. Effects of nitrogen fertilization and frequency of cutting on the yield and composition of napier grass in Puerto Rico. Journal of Agriculture of the University of Puerto Rico, Rio Piedras, v. 43, n. 4, p. 215-227, Dic. 1959. 